\title{
MATLAB/Simulink ile tek-makinalı sonsuz-baralı bir güç sisteminin kararlılık analizi
}

\author{
Serdar EKINC $\dot{I}^{1}{ }^{*}$, Baran HEKIMOĞLU ${ }^{2}$ \\ ${ }^{1}$ Batman Üniversitesi Müh.-Mim. Fak. Bilgisayar Müh. Böl., Batı Raman Kampüsü, Batman. \\ ${ }^{2}$ Batman Üniversitesi Müh.-Mim. Fak. Elektrik-Elektronik Müh., Batı Raman Kampüsü, Batman. \\ Geliş Tarihi (Recived Date): 16.10.2017 \\ Kabul Tarihi (Accepted Date): 24.03.2018
}

\section{Özet}

Bu makalede tek-makinalı sonsuz-baralı (TMSB) bir güç sisteminin elektromekanik salınımlarının küçük-işaret analizini ve geçici hal kararlılık analizini öğretmek için bir eğitim aracı sunuldu. İlgili araç dinamik ve doğrusal olmayan sistemlerin modellenmesi, analizi ve simülasyonu için güçlü bir yazılım paketi olan MATLAB/Simulink ortamında geliştirilmiştir. Geliştirilen MATLAB/Simulink tabanlı programın en belirgin özellikleri kullanım basitliği, esneklik ile kolay anlaşılır ve kolayca değiştirilebilen çok iyi yapılandırılmış kodlardır. Simülasyon sonuçları, geliştirilen programın elektrik güç sistemi kararlılık çalışmaları için güçlü ve elverişli bir araç olduğunu göstermiştir. Bununla birlikte, geliştirilen program ögrenciler ile araştırmacıların açısal kararlılık olgusunu anlaması için çok yararlıdır.

Anahtar kelimeler: MATLAB, Simulink, güç sistemi kararlılığı, güç sistemi modellemesi, ĕgitimsel araç.

\section{Stability analysis of a single-machine infinite-bus power system with MATLAB/Simulink}

\begin{abstract}
An educational tool for teaching small-signal analysis of electromechanical oscillations and transient stability analysis of a single-machine infinite-bus (SMIB) power system is presented in this paper. The corresponding tool has been developed within the environment of MATLAB/Simulink, which is a potent software package for modeling, analysis and simulating dynamical and nonlinear systems. The most prominent features of the developed MATLAB/Simulink-based program are simplicity of use, flexibility, and
\end{abstract}

\footnotetext{
"Serdar EKINCİ, serdar.ekinci@batman.edu.tr, http://orcid.org/0000-0002-7673-2553

Baran HEKIMOĞLU, baran.hekimoglu@batman.edu.tr, http://orcid.org/0000-0002-1839-025X
} 
very well-structured code, which is easy to understand and can be easily modified. Simulation results have demonstrated that the developed program is a powerful and favorable tool for electric power system stability studies. In addition, the developed program is very helpful to understand the angle stability phenomena for students and researchers.

Keywords: MATLAB, Simulink, power system stability, power system modeling, educational tool.

\section{Giriș}

Elektrik güç sistemlerinin en önemli ve en karmaşık çalışma konularından biri kararlılıktır. Güç sisteminin elektromekanik dinamik davranışı üzerindeki arızaların etkisini araştıran kararlılık çalışmaları geçici hal ve sürekli hal kararlılığı olmak üzere iki ana gruba ayrılır [1]. Sürekli hal kararlılığı ya da diğer adıyla küçük işaret kararlılığı, güç sisteminin küçük bozulmalar altında senkronizmayı koruma yeteneği olarak tanımlanır. Geçici hal kararlılığı ise büyük arızaya maruz kalan güç sisteminin senkronizasyonda kalma yeteneğidir. İletim sistemlerindeki arızalar, ani yük değişimleri, üretim birimlerinin kaybı, önemli iletim hatlarının devre dışı kalması ve hat anahtarlamaları büyük arıza örnekleri arasında sayılmaktadır [1, 2]. Bu tür arızalarda sistem cevabı, generatör rotor açıları, yük akışları, bara gerilimleri ve diğer sistem değişkenlerinin büyük sapmalarına yol açar. Sürekli hal kararlılığı yalnızca başlangıç çalışma koşullarının bir fonksiyonu olmasına rağmen, geçici hal kararlılığı ise başlangıç çalışma koşulları ve bozucu etkilerin toplamından oluşan bir fonksiyonudur. Ayrıca, geçici hal kararlılığı çalışmaları büyük arızaları içerir ve sistem denklemlerini doğrusal hale getirmesine izin vermez. Bu sayılan vasıflar nedeniyle, geçici hal kararlılık analizi önemli ölçüde karmaşıktır [3]. Düşünülen farklı bozucu etkiler (büyük arıza) için tekrarlı analizlerin yapılması gereklidir. Geçici hal kararlılık analizi çalışmalarında sıklıkla rastlanılan bozucu etkiler çeşitli kısa devrelerdir. Bunların dışında, bağlı makinanın maksimum hızlanmasına sebep olduğu için generatör barasındaki üç fazlı kısa devre en ciddi arıza türü sayılmaktadır. [1,2].

Güç sistemleri analizi, dinamiği ve kontrolü gibi çalışma alanlarında üstün performans sergileyen ve yüksek seviyeli program dillerinden olan MATLAB, MATHEMATICA ve MODELICA son yirmi yıldır araştırmacılar ve öğrenciler tarafından sıkça kullanılmaktadır [4]. Ancak araştırma ve eğitim alanlarında kullanıcı tercihlerinden dolayı MATLAB açık ara öndedir. MATLAB program dilinin en göze çarpan özellikleri ise matris tabanlı programlanması, mükemmel grafik çizim yetilerine sahip olması ve kontrol şeması tasarımını gayet kolaylaştıran bir grafik ortamı olan Simulink programını barındırmasıdır $[1,3]$.

MATLAB ile uyumlu çalışan ve çok önemli görsel bir yazılım ortamı olan Simulink dinamik ve doğrusal olmayan sistemlerin modellenmesinde, tasarımında ve simülasyonunda kullanılır. Simulink kütüphanesinde bulunan ön tanımlı bloklar sayesinde sürekli ve ayrık sistemlerin modellerini basitçe inşa eder ve simülasyon sonuçlarını osiloskop ile görüntüler. Simulink programının kullanımı, başta matematik ve mühendislik dalları olmak üzere ve aynı zamanda güç sistemleri alanlarında çok hızlı şekilde artmaktadır [5-11]. 
$\mathrm{Bu}$ makalenin ana amac1, matematiksel temele dayalı, tek-makinalı sonsuz-baralı (TMSB) bir güç sisteminde kararlılık analizi yapabilen, ayrıca eğitim alanında da kullanılabilecek MATLAB/Simulink tabanlı yeni bir paket program geliştirmektir. Tasarlanan program vasıtasıyla TMSB bir güç sistemin başlangıç koşulları elde edilerek doğrusallaştırılmış sistemin öz-değer analizi ve zaman bölgesi simülasyonları kolaylıkla yapılabilir. Programın genişletilebilir olma özelliğini kanıtlamak açısından kontrolsüz sisteme güç sistemi kararlı kılıcısı (PSS) da ilave edilmiştir.

\section{TMSB güç sistemi}

Sonsuz bir baraya bağlı tek makinalı güç sisteminin diferansiyel-cebirsel doğrusal olmayan modeli genel olarak aşağıdaki şekilde tanımlanır [12].

$\dot{x}=f(x, y, u)$

$0=g(x, y)$

burada $x$ durum vektörü ve $y$ cebirsel değişkenler vektörüdür. $f$ diferansiyel denklemlerden ve $g$ stator cebirsel ve şebeke denklemlerinden oluşur. $x^{o}, y^{o}$ ve $u^{o}$ çalışma noktaları alınmak suretiyle $x=x^{o}+\Delta x, y=y^{o}+\Delta y \quad$ ve $u=u^{o}+\Delta u$ bozucu işarete maruz kalmış değişkenler olarak alınsın. Böylece (1) denklemi doğrusallaştırılırsa,

$$
\begin{aligned}
\Delta \dot{x} & =A \Delta x+B \Delta y+E \Delta u \\
0 & =C \Delta x+D \Delta y
\end{aligned}
$$

elde edilmiş olur.

\subsection{Temel denklemler}

Sonsuz baraya bir $X_{e}$ dış reaktans ve $R_{e}$ direnci vasıtasıyla bağlı tek makinalı sistemin şematik gösterimi Şekil 1'de verilmiştir. Generatör barasında yerel yükün olmadığ varsayımı yapılmıştır. Uyarma eklenmemiş akı-sönümlü modele ilişkin senkron makinanın diferansiyel ve cebirsel denklemleri aşağıda verildiği gibi ifade edilir [12]:

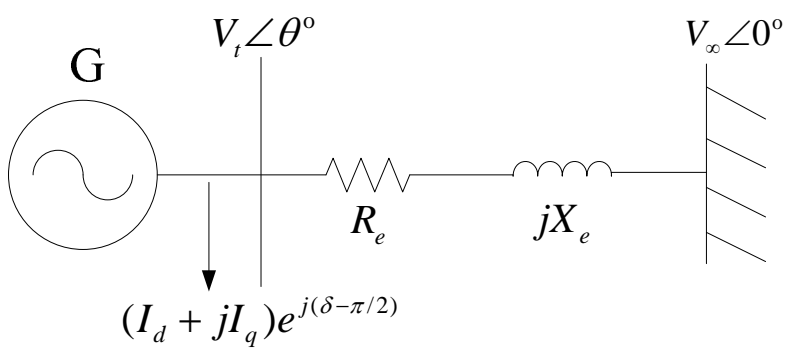

Șekil 1. Tek-makinalı sonsuz-baralı sistem. 


\subsubsection{Diferansiyel denklemler}

$$
\begin{aligned}
& \dot{E}_{q}^{\prime}=-\frac{1}{T_{d o}^{\prime}}\left(E_{q}^{\prime}+\left(X_{d}-X_{d}^{\prime}\right) I_{d}-E_{f d}\right) \\
& \dot{\delta}=\omega-\omega_{s} \\
& \dot{\omega}=\frac{\omega_{s}}{2 H}\left[T_{m}-\left(E_{q}^{\prime} I_{q}+\left(X_{q}-X_{d}^{\prime}\right) I_{d} I_{q}+D\left(\omega-\omega_{s}\right)\right)\right]
\end{aligned}
$$

Yukarıdaki denklemlerde $\delta$ rotor açısal konumu, $\omega$ rotor açısal hızı, $\omega_{s}$ senkron açısal hızı, $V_{\infty}$ sonsuz bara gerilimi, $V_{t}$ generatör uç gerilimi, $H$ senkron generatör atalet sabiti, $D$ sönüm katsayısı, $E_{f d}$ uyarma gerilimi, $T_{d o}^{\prime} d$-ekseni geçici zaman sabiti, $E_{q}^{\prime} q$ ekseni geçici gerilimi, $X_{d}$ ve $X_{q} d$-ekseni ve $q$-ekseni senkron reaktans bileşenleri, $X_{d}^{\prime}$ $d$-ekseni geçici reaktansı, $I_{d}$ ve $I_{q} d$-ekseni ve $q$-ekseni endüvi akımları ve $T_{m}$ mekanik güç girişi olarak tanımlanmaktadır.

\subsubsection{Stator cebirsel denklemleri}

$V_{t} \sin (\delta-\theta)+R_{s} I_{d}-X_{q} I_{q}=0$

$E_{q}^{\prime}-V_{t} \cos (\delta-\theta)-R_{s} I_{d}-X_{d}^{\prime} I_{d}=0$

$R_{s}=0$ (stator direnci) olduğu varsayımı yapılarak ve generatör uç geriliminin büyüklüğü $V_{t}$ olarak tanımlanırsa, önceki iki denklem aşağıdaki şekilde indirgenir.

$$
\begin{aligned}
& X_{q} I_{q}-V_{t} \sin (\delta-\theta)=0 \\
& E_{q}^{\prime}-V_{t} \cos (\delta-\theta)-X_{d}^{\prime} I_{d}=0
\end{aligned}
$$

$\left(V_{d}+j V_{q}\right) e^{j(\delta-\pi / 2)}=V_{t} e^{j \theta}$ eşitliğinden $V_{d}=V_{t} \sin (\delta-\theta)$ ve $V_{q}=V_{t} \cos (\delta-\theta)$ olarak bulunur. $V_{d}$ ve $V_{q}$ (8) ve (9) nolu denklemlerde yerine koyulursa, stator cebirsel denklemleri,

$$
\begin{aligned}
& X_{q} I_{q}-V_{d}=0 \\
& E_{q}^{\prime}-V_{q}-X_{d}^{\prime} I_{d}=0
\end{aligned}
$$

şeklinde olur.

\subsection{3. Şebeke denklemleri}

Sonsuz barada sıfır faz açısı olduğu kabul edilerek şebeke denklemi yazılırsa: 
$I_{G} e^{j \gamma}=\left(I_{d}+j I_{q}\right) e^{j(\delta-\pi / 2)}=\frac{\left(V_{d}+j V_{q}\right) e^{j(\delta-\pi / 2)}-V_{\infty} \angle 0^{\circ}}{R_{e}+j X_{e}}$

Çapraz çarpmadan sonra gerçek ve sanal kısımlar ayrıldığında;

$R_{e} I_{d}-X_{e} I_{q}=V_{d}-V_{\infty} \sin \delta$

$X_{e} I_{d}+R_{e} I_{q}=V_{q}-V_{\infty} \cos \delta$

denklemleri elde edilir. Böylece tek makinalı sonsuz baralı sistem için (3)-(5) diferansiyel denklemlerini ve (10), (11), (13), (14) cebirsel denklemlerini bulmuş olduk.

\subsection{Doğrusallaştırma işlemi ve $K_{1}-K_{6}$ sabitlerinin türetilmesi}

Adım 1: (10) ve (11) stator cebirsel denklemleri doğrusal hale getirilerek matris formda yazılırsa:

$\left[\begin{array}{c}\Delta V_{d} \\ \Delta V_{q}\end{array}\right]=\left[\begin{array}{cc}0 & X_{q} \\ -X_{d}^{\prime} & 0\end{array}\right]\left[\begin{array}{c}\Delta I_{d} \\ \Delta I_{q}\end{array}\right]+\left[\begin{array}{c}0 \\ \Delta E_{q}^{\prime}\end{array}\right]$

Adım 2: (13) ve (14) yük-akışı denklemleri doğrusal hale getirilerek matris formda yazılırsa:

$\left[\begin{array}{c}\Delta V_{d} \\ \Delta V_{q}\end{array}\right]=\left[\begin{array}{cc}R_{e} & -X_{e} \\ X_{e} & R_{e}\end{array}\right]\left[\begin{array}{l}\Delta I_{d} \\ \Delta I_{q}\end{array}\right]+\left[\begin{array}{c}V_{\infty} \cos \delta^{o} \\ -V_{\infty} \sin \delta^{o}\end{array}\right] \Delta \delta$

Adım 3: (15) ve (16) denklemlerin sağ tarafları eşitlenip basitleştirilirse,

$\left[\begin{array}{cc}R_{e} & -\left(X_{e}+X_{q}\right) \\ \left(X_{e}+X_{d}^{\prime}\right) & R_{e}\end{array}\right]\left[\begin{array}{c}\Delta I_{d} \\ \Delta I_{q}\end{array}\right]=\left[\begin{array}{c}0 \\ \Delta E_{q}^{\prime}\end{array}\right]+\left[\begin{array}{c}-V_{\infty} \cos \delta^{o} \\ V_{\infty} \sin \delta^{o}\end{array}\right] \Delta \delta$

Ayrıca 2×2’lik bir matrisin tersi özelliğinden,

$\left[\begin{array}{cc}R_{e} & -\left(X_{e}+X_{q}\right) \\ \left(X_{e}+X_{d}^{\prime}\right) & R_{e}\end{array}\right]^{-1}=\frac{1}{\Delta}\left[\begin{array}{cc}R_{e} & \left(X_{e}+X_{q}\right) \\ -\left(X_{e}+X_{d}^{\prime}\right) & R_{e}\end{array}\right]$

Yukarıdaki denklemdeki $\Delta$ determinantı $\Delta=R_{e}^{2}+\left(X_{e}+X_{q}\right)\left(X_{e}+X_{d}^{\prime}\right) \quad$ olarak verilebilir. (17) denklemindeki $\Delta I_{d}$ ve $\Delta I_{q}$ basitleştirme işlemlerinden sonra matris formda aşağıdaki gibi elde edilir.

$\left[\begin{array}{c}\Delta I_{d} \\ \Delta I_{q}\end{array}\right]=\frac{1}{\Delta}\left[\begin{array}{c:c}\left(X_{e}+X_{q}\right) & -R_{e} V_{\infty} \cos \delta^{o}+V_{\infty} \sin \delta^{o}\left(X_{e}+X_{q}\right) \\ \hdashline R_{e} & R_{e} V_{\infty} \sin \delta^{o}+V_{\infty} \cos \delta^{o}\left(X_{e}+X_{d}^{\prime}\right)\end{array}\right]\left[\begin{array}{c}\Delta E_{q}^{\prime} \\ \Delta \delta\end{array}\right]$ 
Adım 4: $\mathrm{Bu}$ adımda (3)-(5) diferansiyel denklemleri doğrusallaştırılır. $v=\omega / \omega_{\mathrm{s}}$ normalize edilmiş frekans olarak tanımlansın. Böylece doğrusal hale getirilmiş diferansiyel denklemler matris formda aşağıda verildiği gibi olur.

$$
\begin{aligned}
{\left[\begin{array}{c}
\Delta \dot{E}_{q}^{\prime} \\
\Delta \dot{\delta} \\
\Delta \dot{v}
\end{array}\right] } & =\left[\begin{array}{ccc}
-\frac{1}{T_{d o}^{\prime}} & 0 & 0 \\
0 & 0 & \omega_{s} \\
-\frac{I_{q}^{o}}{2 H} & 0 & -\frac{D \omega_{s}}{2 H}
\end{array}\right]\left[\begin{array}{c}
\Delta E_{q}^{\prime} \\
\Delta \delta \\
\Delta v
\end{array}\right] \\
+ & {\left[\begin{array}{cc}
-\frac{\left(X_{d}-X_{d}^{\prime}\right)}{T_{d o}^{\prime}} & 0 \\
0 & \frac{I_{d}^{o}\left(X_{d}^{\prime}-X_{q}\right)-E_{q}^{\prime o}}{2 H}
\end{array}\right]\left[\begin{array}{c}
\Delta I_{d} \\
\Delta I_{q}
\end{array}\right]+\left[\begin{array}{cc}
\frac{1}{T_{d o}^{\prime}} & 0 \\
0 & 0 \\
0 & \frac{1}{2 H}
\end{array}\right]\left[\begin{array}{c}
\Delta E_{f d} \\
\Delta T_{m}
\end{array}\right] }
\end{aligned}
$$

Adım 5: Bu adımda doğrusallaştırılmış denklemler $K$ sabit terimleriyle ifade edilir. (19) denkleminde bulunan $\Delta \mathrm{I}_{\mathrm{d}}$ ve $\Delta \mathrm{I}_{\mathrm{q}}(20)$ denkleminde yerine koyulursa,

$$
\begin{aligned}
& \Delta \dot{E}_{q}^{\prime}=-\frac{1}{K_{3} T_{d o}^{\prime}} \Delta E_{q}^{\prime}-\frac{K_{4}}{T_{d o}^{\prime}} \Delta \delta+\frac{1}{T_{d o}^{\prime}} \Delta E_{f d} \\
& \Delta \dot{\delta}=\omega_{s} \Delta v \\
& \Delta \dot{v}=-\frac{K_{2}}{2 H} \Delta E_{q}^{\prime}-\frac{K_{1}}{2 H} \Delta \delta-\frac{D \omega_{s}}{2 H} \Delta v+\frac{1}{2 H} \Delta T_{m}
\end{aligned}
$$

Yukarıdaki (21)-(23) denklemlerinde,

$$
\begin{aligned}
\frac{1}{K_{3}}= & 1+\frac{\left(X_{d}-X_{d}^{\prime}\right)\left(X_{q}+X_{e}\right)}{\Delta} \\
K_{4}= & \frac{V_{\infty}\left(X_{d}-X_{d}^{\prime}\right)}{\Delta}\left[\left(X_{q}+X_{e}\right) \sin \delta^{o}-R_{e} \cos \delta^{o}\right] \\
K_{2}= & \frac{1}{\Delta}\left[I_{q}^{o} \Delta-I_{q}^{o}\left(X_{d}^{\prime}-X_{q}\right)\left(X_{q}+X_{e}\right)-R_{e}\left(X_{d}^{\prime}-X_{q}\right) I_{d}^{o}+R_{e} E_{q}^{o}\right] \\
K_{1}= & -\frac{1}{\Delta}\left[I_{q}^{o} V_{\infty}\left(X_{d}^{\prime}-X_{q}\right)\left\{\left(X_{q}+X_{e}\right) \sin \delta^{o}-R_{e} \cos \delta^{o}\right\}\right. \\
& \left.+V_{\infty}\left\{\left(X_{d}^{\prime}-X_{q}\right) I_{d}^{o}-E_{q}^{o}\right\}\left\{\left(X_{d}^{\prime}+X_{e}\right) \cos \delta^{o}+R_{e} \sin \delta^{o}\right\}\right]
\end{aligned}
$$

Adım 6: Generatör uç geriliminin doğrusallaştırılması aşağıdaki gibidir:

$$
V_{t}^{2}=V_{d}^{2}+V_{q}^{2}
$$


(28) denklemi doğrusallaştırılırsa,

$2 V_{t}^{o} \Delta V_{t}=2 V_{d}^{o} \Delta V_{d}+2 V_{q}^{o} \Delta V_{q}$

Böylece son denklem,

$$
\Delta V_{t}=\frac{V_{d}^{o}}{V_{t}^{o}} \Delta V_{d}+\frac{V_{q}^{o}}{V_{t}^{o}} \Delta V_{q}
$$

olur. (19) denklemini (15) denkleminde yerine yazarsak,

$$
\begin{aligned}
{\left[\begin{array}{c}
\Delta V_{d} \\
\Delta V_{q}
\end{array}\right]=} & \frac{1}{\Delta}\left[\begin{array}{c:c}
X_{q} R_{e} & X_{q}\left(R_{e} V_{\infty} \sin \delta^{o}+\left(X_{e}+X_{d}^{\prime}\right) V_{\infty} \cos \delta^{o}\right) \\
\hdashline-X_{d}^{\prime}\left(X_{e}+X_{q}\right) & -X_{d}^{\prime}\left(-R_{e} V_{\infty} \cos \delta^{o}+\left(X_{e}+X_{q}\right) V_{\infty} \sin \delta^{o}\right)
\end{array}\right]\left[\begin{array}{c}
\Delta E_{q}^{\prime} \\
\Delta \delta
\end{array}\right] \\
& +\left[\begin{array}{c}
0 \\
\Delta E_{q}^{\prime}
\end{array}\right]
\end{aligned}
$$

elde edilir. Son olarak (31) denklemini (30) denkleminde yerine yazarsak aşağıdaki denklem bulunur.

$$
\Delta V_{t}=K_{5} \Delta \delta+K_{6} \Delta E_{q}^{\prime}
$$

Son denklemdeki $\mathrm{K}_{5}$ ve $\mathrm{K}_{6}$ sabitleri ise,

$$
\begin{aligned}
K_{5}= & \frac{1}{\Delta}\left\{\frac{V_{d}^{o}}{V_{t}^{o}} X_{q}\left[R_{e} V_{\infty} \sin \delta^{o}+\left(X_{e}+X_{d}^{\prime}\right) V_{\infty} \cos \delta^{o}\right]\right. \\
& \left.+\frac{V_{q}^{o}}{V_{t}^{o}} X_{d}^{\prime}\left[R_{e} V_{\infty} \cos \delta^{o}-\left(X_{e}+X_{q}\right) V_{\infty} \sin \delta^{o}\right]\right\} \\
K_{6}= & \frac{1}{\Delta}\left\{\frac{V_{d}^{o}}{V_{t}^{o}} X_{q} R_{e}-\frac{V_{q}^{o}}{V_{t}^{o}} X_{d}^{\prime}\left(X_{e}+X_{q}\right)\right\}+\frac{V_{q}^{o}}{V_{t}^{o}}
\end{aligned}
$$

Yerel düşük-frekanslı salınım çalışmaları için türetilen $\mathrm{K}_{1}-\mathrm{K}_{6}$ sabitleri Heffron-Philips ve daha sonraları DeMello-Concordia tarafından geliştirilmiştir [12, 13].

\subsection{Senkronizasyon ve sönüm momentleri}

Şekil 1'deki tek-makinalı sonsuz-baralı sisteme durum-uzayı denklemi aşağıda verilen hızlı uyarma ilave edilirse [12],

$$
T_{a} \dot{E}_{f d}=-E_{f d}+K_{a}\left(V_{r e f}-V_{t}\right)
$$

Yukarıdaki denklemde $T_{a}$ uyarma zaman sabiti, $K_{a}$ uyarma kazancı ve $V_{\text {ref }}$ referans gerilimini göstermektedir. Son denklem doğrusal hale getirilirse, 


$$
T_{a} \Delta \dot{E}_{f d}=-\Delta E_{f d}+K_{a}\left(\Delta V_{r e f}-\Delta V_{t}\right)
$$

Böylece (21)-(23) makine diferansiyel denklemlerini, (36) uyarma denklemini ve (32) cebirsel denklemini blok diyagram formunda Şekil 2'de gösterildiği şekilde yerine yerleştirilir. Şekilde $v$ normalize edilmiş frekans ve $\omega(\mathrm{rad} / \mathrm{s})$ de gösterilmiştir.

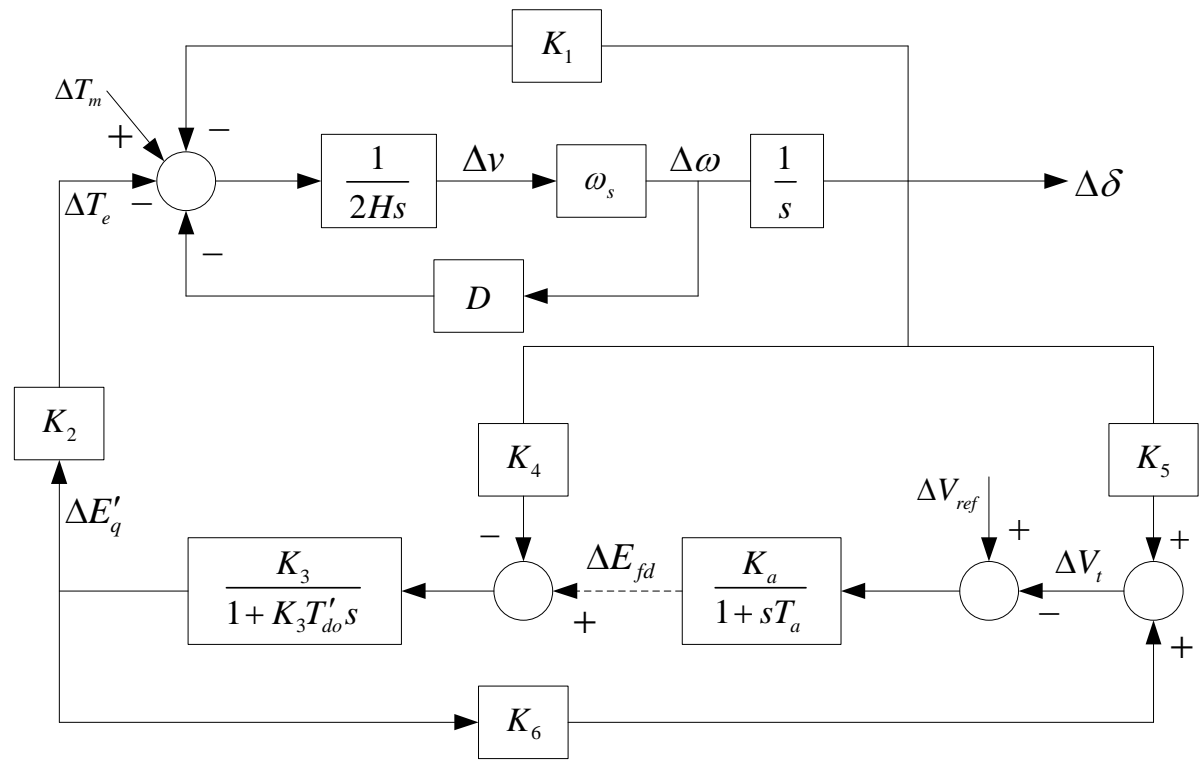

Şekil 2. Doğrusallaştırılmış TMSB sistemin blok diyagramı (Noktalı kısım uyarmayı gösterir).

\subsection{Durum uzayı modeli kullanılarak küçük işaret kararlılık analizi}

Senkron makinanın durum uzayı gösterimi (21)-(23) denklemleri matris formda birlikte yazılınca elde edilir. $\Delta \mathrm{T}_{\mathrm{m}}=0$ varsayımı yapılarak, uyarma ilavesiz TMSB sistemin durum uzayı modeli aşağıda verildiği biçimdedir [13].

$\left[\begin{array}{c}\Delta \dot{E}_{q}^{\prime} \\ \Delta \dot{\delta} \\ \Delta \dot{v}\end{array}\right]=\left[\begin{array}{ccc}-\frac{1}{K_{3} T_{d o}^{\prime}} & -\frac{K_{4}}{T_{d o}^{\prime}} & 0 \\ 0 & 0 & \omega_{s} \\ -\frac{K_{2}}{2 H} & -\frac{K_{1}}{2 H} & -\frac{D \omega_{s}}{2 H}\end{array}\right]\left[\begin{array}{c}\Delta E_{q}^{\prime} \\ \Delta \delta \\ \Delta v\end{array}\right]+\left[\begin{array}{c}\frac{1}{T_{d o}^{\prime}} \\ 0 \\ 0\end{array}\right] \Delta E_{f d}$

Yukarıdaki denklemde $\Delta \mathrm{E}_{\mathrm{fd}}$ alan gerilimindeki pertürbasyondür. Uyarma olmadığında makinanın manuel kontrolde olduğu söylenir. Matrisin genellikle 1-3 Hz arasındaki elektromekanik moda karşılık gelen bir çift kompleks özdeğeri ve akı-sönümlü moda karşılık gelen bir negatif gerçek özdeğeri vardır. Uyarma olmadığında (diğer bir deyişle $\mathrm{K}_{\mathrm{a}}=0$ olduğunda) Şekil 2'deki blok diyagramda üç çevrim mevcuttur. Üsteki iki çevrim kompleks özdeğer çiftine karşılık gelen moment-açı çevrimleri olarak adlandırılır ve $\mathrm{K}_{4}$ yoluyla $\Delta E_{q}^{\prime}$ 'e bağlı olan alttaki çevrim ise gerçek özdeğer içindir. Alt çevrim pozitif geri-beslemeye katkı sağlar ve bunun sonucu olarak moment-açı özdeğerleri sol-yarı düzleme ve negatif gerçek özdeğer ise sağ-yarı düzleme hareket etme eğiliminde olurlar [13]. 
Uyarma sisteminin etkisini irdelemek için basitleştirilmiş gösterim vasıtasıyla uyarma eklersek, durum uzayı denklemi $\Delta \mathrm{E}_{\mathrm{fd}}$ bir durum değişkeni yapılarak değișecektir. (32) denklemindeki $\Delta \mathrm{V}_{\mathrm{t}}(36)$ denkleminde yerine yazılırsa aşağıdaki sonuç elde edilir.

$$
\begin{aligned}
\Delta \dot{E}_{f d} & =-\frac{1}{T_{a}} \Delta E_{f d}+\frac{K_{a}}{T_{a}}\left(\Delta V_{r e f}-\Delta V_{t}\right) \\
& =-\frac{1}{T_{a}} \Delta E_{f d}+\frac{K_{a}}{T_{a}} \Delta V_{r e f}-\frac{K_{a} K_{5}}{T_{a}} \Delta \delta-\frac{K_{a} K_{6}}{T_{a}} \Delta E_{q}^{\prime}
\end{aligned}
$$

Uyarma ilave bir negatif gerçek özdeğer oluşturur. Şekil 2 için tüm durum uzayı modeli (39)'deki gibi olur.

$$
\left[\begin{array}{c}
\Delta \dot{E}_{q}^{\prime} \\
\Delta \dot{\delta} \\
\Delta \dot{v} \\
\Delta \dot{E}_{f d}
\end{array}\right]=\underbrace{\left[\begin{array}{cccc}
-\frac{1}{K_{3} T_{d o}^{\prime}} & -\frac{K_{4}}{T_{d o}^{\prime}} & 0 & \frac{1}{T_{d o}^{\prime}} \\
0 & 0 & \omega_{s} & 0 \\
-\frac{K_{2}}{2 H} & -\frac{K_{1}}{2 H} & -\frac{D \omega_{s}}{2 H} & 0 \\
-\frac{K_{a} K_{6}}{T_{a}} & -\frac{K_{a} K_{5}}{T_{a}} & 0 & -\frac{1}{T_{a}}
\end{array}\right]}_{A_{\text {exciter }}}\left[\begin{array}{c}
\Delta E_{q}^{\prime} \\
\Delta \delta \\
\Delta v \\
\Delta E_{f d}
\end{array}\right]+\left[\begin{array}{c}
0 \\
0 \\
0 \\
\frac{K_{a}}{T_{a}}
\end{array}\right] \Delta V_{r e f}
$$

\subsection{Başlangıç koşullarının hesaplanması}

TMSB sistemin akı-sönümlü modeli için durum değişkenlerin başlangıç koşulları (sürekli hal değerleri) sistematik şekilde aşağıdaki adımlar takip edilerek yapılır [12]. İşlemler yapılırken cebirsel ve durum değişkenlerdeki $O$ üst indisi göz ardı edildi.

$\underline{\operatorname{Adim} 1}$ : $I_{G} e^{j \gamma}=\frac{V_{t} \angle \theta^{o}-V_{\infty} \angle 0^{\circ}}{R_{e}+j X_{e}}$ 'den $I_{G}$ ve $\gamma$ hesaplanır.

Adım 2: $V_{t} e^{j \theta}+\left(R_{s}+j X_{q}\right) I_{G} e^{j \gamma}$ 'nın açısından $\delta$ hesaplanır.

Adım 3: $\quad I_{d}+j I_{q}=I_{G} e^{j \gamma} e^{-j(\delta-\pi / 2)}$ denkleminden yararlanarak $I_{d}=I_{G} \sin (\delta-\gamma)$ ve $I_{q}=I_{G} \cos (\delta-\gamma)$ olarak hesaplanır.

$\underline{\operatorname{Adım} 4:} V_{d}+j V_{q}=V_{t} e^{j \theta} e^{-j(\delta-\pi / 2)}$ denkleminden yararlanarak $V_{d}=V_{t} \sin (\delta-\theta) \quad$ ve $V_{q}=V_{t} \cos (\delta-\theta)$ olarak hesaplanır.

Adim 5: (11) denkleminden $E_{q}^{\prime}=V_{q}+X_{d}^{\prime} I_{d}$ olarak hesaplanır.

Adım 6: (3)-(5) ve (35) denklemlerindeki tüm türevler sıfıra eşitlenmek suretiyle $E_{f d}=E_{q}^{\prime}+\left(X_{d}-X_{d}^{\prime}\right) I_{d}, \quad V_{r e f}=V_{t}+\frac{E_{f d}}{K_{a}}, \quad \omega_{s}=2 \pi f \quad$ ve $\quad T_{m}=E_{q}^{\prime} I_{q}+\left(X_{q}-X_{d}^{\prime}\right) I_{d} I_{q}$ olarak bulunur.

$\mathrm{Bu}$ adımlar yapılarak başlangıç değerlerin hesaplanması biter. Bu başlangıç değerleri küçük işaret kararlılık analizi ve geçici hal kararlılık çalışmalarında sistem koşullarını bilmemize olanak sağlar. 


\section{Güç sistemi kararlı kılıcılar}

Çalışmanın bu kısmında, düşük-frekanslı salınımları sönümlemek maksadıyla kullanılan güç sistemi kararlı kılıcısı (PSS) tartışılacaktır. Şekil 3'te basit TMSB bir sistem gösterilmiştir. $\mathrm{Bu}$ sistemde küçük işaret salınımlarını iyileştirmek için bir PSS mevcuttur ve ayrıca makine hızlı uyarma ile donatılmıştır.

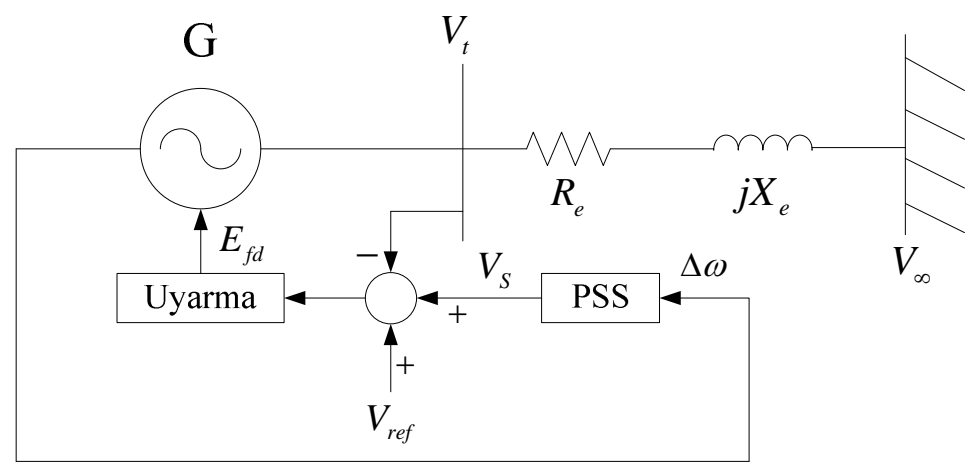

Şekil 3. Uyarma ve PSS ilave edilmiş tek-makinalı sonsuz-baralı sistem.

PSS uyarmasını kontrol ederek generatör rotor salınımlarını bastırmak için bir çeşit elektrik-moment bileșeni üreten faz ilerlemeli-gerilemeli bir kompansatördür [3]. Basit yapısı ve uygulama kolaylığı özellikleri nedeniyle modern güç sistemi şebekelerinin vazgeçilmez tercihidir. Hız sapması girişli tek-aşamalı PSS'nin temel blok diyagramı Şekil 4'te verilmiştir. Şekil 4'te gösterilen güç sistemi kararlı kılıcısının kazancı $K_{P S S}$, yüksek geçiren filtre devre zaman sabiti $T_{W}$ (kritik bir değer olmamakla beraber 1-20 s aralığındadır) ve faz kompanzasyonu zaman sabitleri ise $\mathrm{T}_{1}$ ve $\mathrm{T}_{2}$ 'dir $[2,12]$.

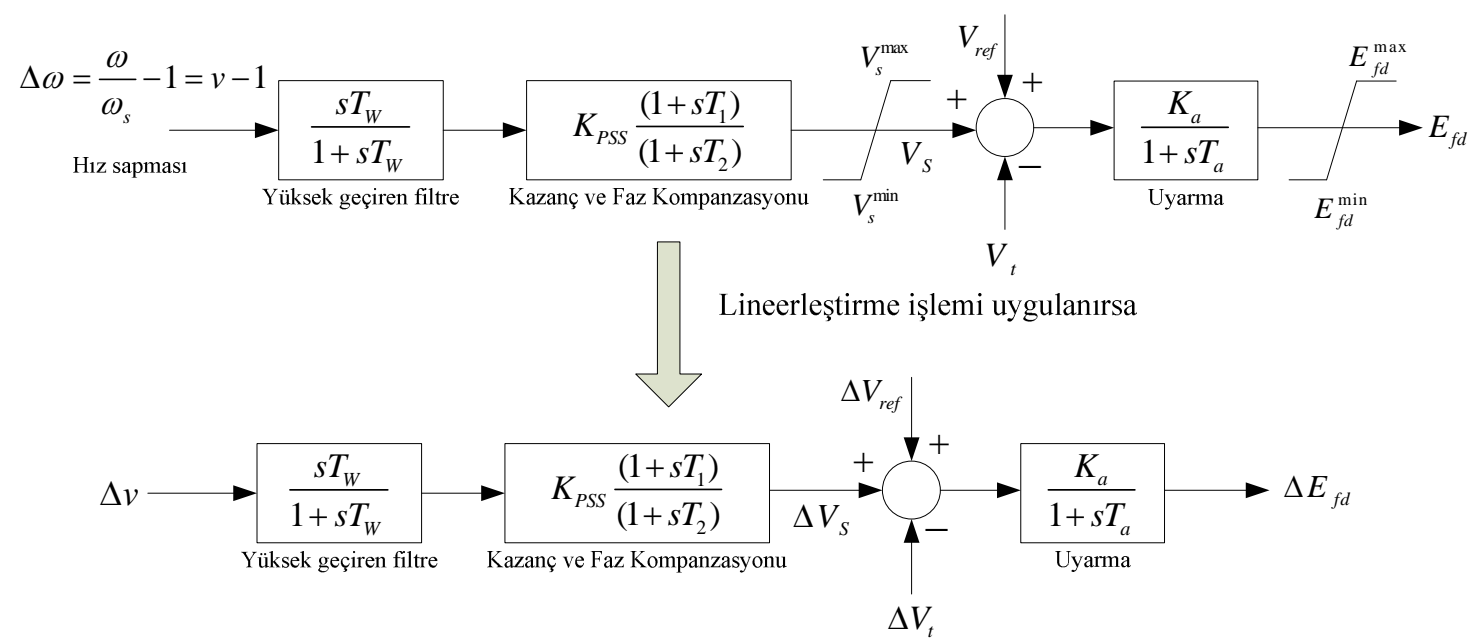

Şekil 4. Uyarma sistemi ve PSS için fonksiyonel blok diyagramı.

Temizleme bloku (yüksek geçiren filtre) ihmal edilerek PSS'den dolayı eklenen durum denklemi yazılıp doğrusal hale getirilirse aşağıdaki denklem elde edilir. 


$$
\begin{aligned}
\Delta \dot{V}_{S} & =-\frac{1}{T_{2}} \Delta V_{s}+\frac{K_{P S S}}{T_{2}} \Delta v+\frac{K_{P S S} T_{1}}{T_{2}} \Delta \dot{v} \\
& =-\frac{1}{T_{2}} \Delta V_{s}+\left(\frac{K_{P S S}}{T_{2}}-\frac{K_{P S S} T_{1}}{T_{2}} \frac{D \omega_{s}}{2 H}\right) \Delta v+\frac{K_{P S S} T_{1}}{T_{2}}\left(-\frac{K_{2}}{2 H} \Delta E_{q}^{\prime}-\frac{K_{1}}{2 H} \Delta \delta\right)
\end{aligned}
$$

PSS ilave edilmesi durumunda üstteki (40) denklemi TMSB sistemin (39) genel denklemine eklenirse elde edilecek APSS sistem matrisi (41) denkleminde görüldüğü biçimde olacaktır.

$$
A_{P S S}=\left[\begin{array}{ccccc}
-\frac{1}{K_{3} T_{d o}^{\prime}} & -\frac{K_{4}}{T_{d o}^{\prime}} & 0 & \frac{1}{T_{d o}^{\prime}} & 0 \\
0 & 0 & \omega_{s} & 0 & 0 \\
-\frac{K_{2}}{2 H} & -\frac{K_{1}}{2 H} & -\frac{D \omega_{s}}{2 H} & 0 & 0 \\
-\frac{K_{a} K_{6}}{T_{a}} & -\frac{K_{a} K_{5}}{T_{a}} & 0 & -\frac{1}{T_{a}} & \frac{K_{a}}{T_{a}} \\
-\frac{K_{2} T_{1}}{T_{2}}\left(\frac{K_{P S S}}{2 H}\right) & -\frac{K_{1} T_{1}}{T_{2}}\left(\frac{K_{P S S}}{2 H}\right) & \left(\frac{K_{P S S}}{T_{2}}-\frac{K_{P S S} T_{1}}{T_{2}} \frac{D \omega_{s}}{2 H}\right) & 0 & -\frac{1}{T_{2}}
\end{array}\right]
$$

\section{Eğitici programın tanıtılması ve test edilmesi}

$\mathrm{Bu}$ çalışmada tek makinalı güç sisteminin kararlılık çalışmaları için kullanılması önerilen MATLAB/Simulink tabanlı paket programdaki tüm dosyalar ve özellikleri Tablo 1'de verilmiştir.

Tablo 1. Tasarlanan programdaki dosyalar ve işlevleri.

\begin{tabular}{|l|l|}
\hline Dosya Adı & İşlevi \\
\hline TMSB_veri.m & $\begin{array}{l}\text { Örnek güç sisteminin verilerini içerir. Kullanıcı } \\
\text { sistem parametrelerini değiştirebilir. }\end{array}$ \\
\hline baslangic_kosullari.m & Başlangıç koşullarının hesaplanmasını sağlar. \\
\hline kucuk_isaret_kararlilik_analizi.m & $\begin{array}{l}\mathrm{K}_{1}-\mathrm{K}_{6} \text { katsayılarını, sistem matrisini ve özdeğerleri } \\
\text { bulur. }\end{array}$ \\
\hline $\begin{array}{l}\text { rotor_acisi_cizimi.m, } \\
\text { hiz_sapmasi_cizimi.m ve } \\
\text { elektriksel_guc_cizimi.m }\end{array}$ & $\begin{array}{l}\delta \text { rotor açısı, } \Delta \omega \text { rotor hız sapması ve T } \\
\text { güç ęıkışlarının zamana göre sistem cevaplarını } \\
\text { çizdirir. }\end{array}$ \\
\hline gecici_hal_kararlilik_analizi.mdl & $\begin{array}{l}\text { Sistemin doğrusal olmayan modeli üzerinden zaman } \\
\text { bölgesi simülasyonlarını yapar. }\end{array}$ \\
\hline
\end{tabular}

\subsection{Aydınlatıcı sistem örne ği}

TMSB güç sisteminin küçük işaret kararlılığı ve geçici hal kararlılığı olgularını daha iyi kavranabilmesi açısından nümerik bir örnek ele alındı. Şekil 3'teki güç sisteme ilişkin sistem verileri Tablo 2'de verilmiştir. 
Tablo 2. İncelenen sisteme ilişkin sistem parametreleri.

\begin{tabular}{|l|l|}
\hline İletim Hatt1 & $R_{e}=0, X_{e}=0.5 \mathrm{pu}, V_{t} \angle \theta=1 \angle 15^{\circ} \mathrm{pu}$ ve $V_{\infty} \angle 0^{\circ}=1.05 \angle 0^{\circ} \mathrm{pu}$ \\
\hline Generatör & $\begin{array}{l}H=3.2 \mathrm{~s}, T_{d o}^{\prime}=9.6 \mathrm{~s}, R_{s}=0.0 \mathrm{pu}, X_{q}=2.1 \mathrm{pu}, X_{d}=2.5 \mathrm{pu}, \\
X_{d}^{\prime}=0.39 \mathrm{pu}, D=0, f=60\end{array}$ \\
\hline Uyarma & $K_{a}=400, T_{a}=0.2 \mathrm{~s}$ \\
\hline PSS & $K_{P S S}=0.5, T_{1}=0.5 \mathrm{~s}, T_{2}=0.1 \mathrm{~s}$ \\
\hline
\end{tabular}

Bu çalışmada ele alınan sistem [12]'den alınmış olup literatürde çok kullanılmaktadır. Örnek sisteme ilişkin MATLAB kodu Tablo 3'te gösterilmiştir.

Tablo 3. Örnek sistemin verilerine ilişkin MATLAB m-file.

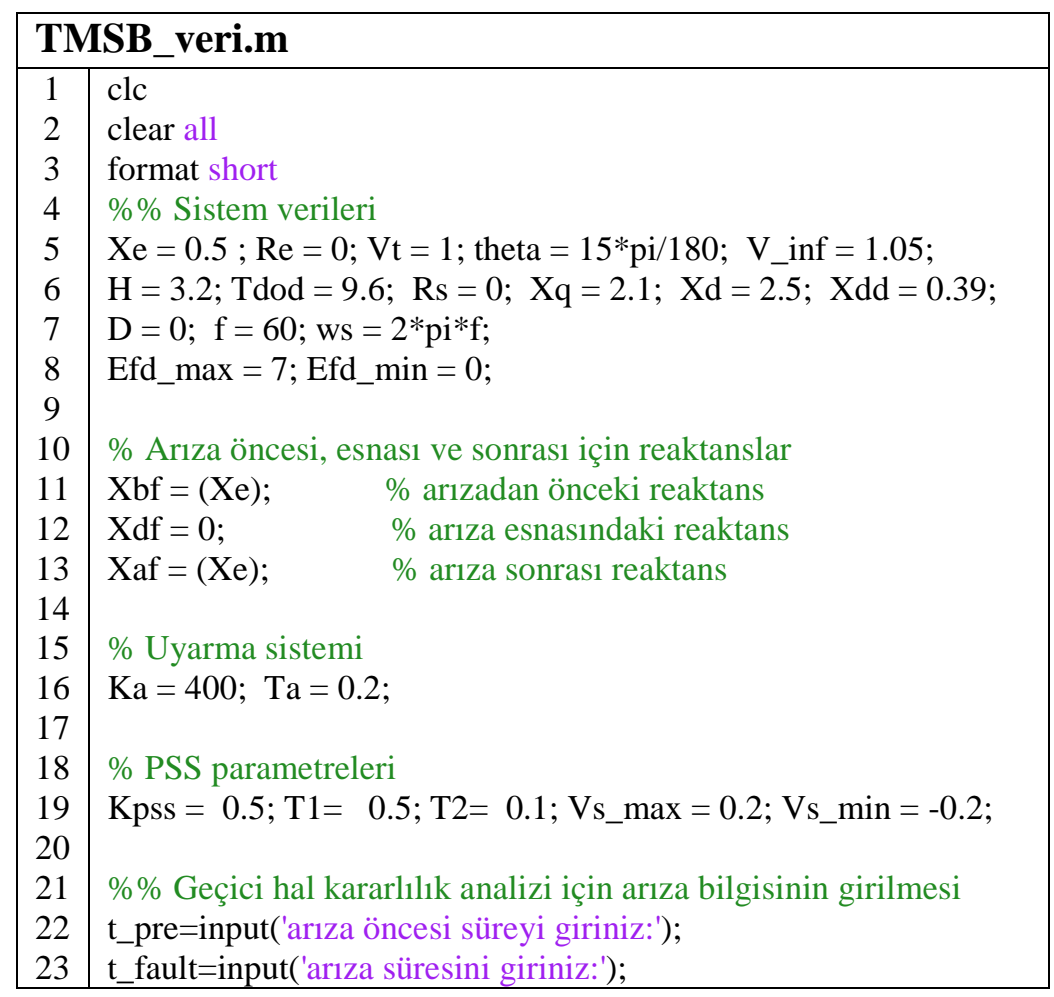

\subsection{MATLAB/Simulink tabanlı program ile başlangıç koşullarının hesaplanması}

Bölüm 2.5'teki başlangıç koşullarının 6 adımda hesaplanması için gerekli MATLAB kodu Tablo 4'te verilmiştir. baslangic_kosullari.m yardımıyla bulunan başlangıç koşulları Tablo 5' te listelenmiştir. 
Tablo 4. Başlangıç koşullarının hesaplanmasına ilişkin MATLAB m-file.

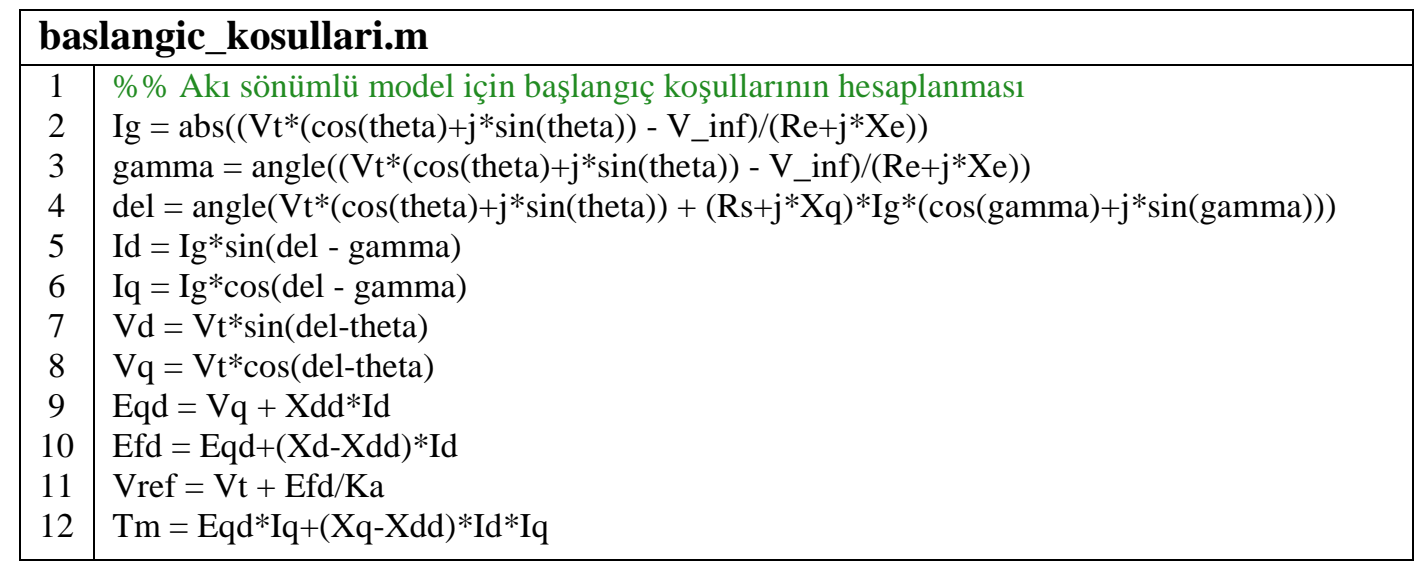

Tablo 5. TMSB sistemin başlangıç çalışma noktaları.

\begin{tabular}{|c|c|}
\hline$I_{G}^{o}$ & 0.54426 \\
\hline$\gamma^{o}$ & 17.996 \\
\hline$\delta^{o}$ & 65.519 \\
\hline$I_{d}^{o}$ & 0.40142 \\
\hline$I_{q}^{o}$ & 0.36754 \\
\hline$V_{d}^{o}$ & 0.77183 \\
\hline$V_{q}^{o}$ & 0.63583 \\
\hline$E_{q}^{o}$ & 0.79238 \\
\hline$E_{f d}^{o}$ & 1.6394 \\
\hline$V_{r e f}^{o}$ & 1.0041 \\
\hline$T_{m}^{o}$ & 0.54352 \\
\hline
\end{tabular}

\subsection{MATLAB/Simulink tabanlı program yardımı ile doğrusallaştırılmış sistemin} özdeğer analizinin yapılması

TMSB örnek güç sisteminin küçük işaret kararlılık analizinin yapılabilmesi için oluşturulan MATLAB tabanlı dosya Tablo 6'da verilmiştir. İlgili m-file çalıştırılırsa, $\mathrm{K}_{1}-\mathrm{K}_{6}$ senkron generatör dinamik model katsayıları ile iki sisteme (uyarma dinamiği ve PSS içeren sistemler) ait sistem matrisleri ve özdeğerleri bulunur. Böylece dinamik model katsayıları $\mathrm{K}_{1}=0.9223, \mathrm{~K}_{2}=1.0737, \mathrm{~K}_{3}=0.2967, \mathrm{~K}_{4}=2.2655, \mathrm{~K}_{5}=0.0050$ ve $\mathrm{K}_{6}=0.3572$ olarak bulunur. Denklem (39)'daki yalnızca uyarma içeren sistemin (PSS'siz sistem) $A_{\text {exciter }}$ matrisi,

$$
A_{\text {exciter }}=\left[\begin{array}{cccc}
-0.3511 & -0.2360 & 0 & 0.1042 \\
0 & 0 & 376.9911 & 0 \\
-0.1678 & -0.1441 & 0 & 0 \\
-714.4124 & -10.0051 & 0 & -5
\end{array}\right]
$$


olarak bulunur. Denklem (41)'deki PSS'li sistemin $A_{P S S}$ matrisi ise,

$$
A_{P S S}=\left[\begin{array}{ccccc}
-0.3511 & -0.2360 & 0 & 0.1042 & 0 \\
0 & 0 & 376.9911 & 0 & 0 \\
-0.1678 & -0.1441 & 0 & 0 & 0 \\
-714.4124 & -10.0051 & 0 & -5 & 2000 \\
-0.4194 & -0.3603 & 5 & 0 & -10
\end{array}\right]
$$

olarak bulunur.

Tablo 6. Küçük işaret kararlılık analizine ilişkin MATLAB m-file.

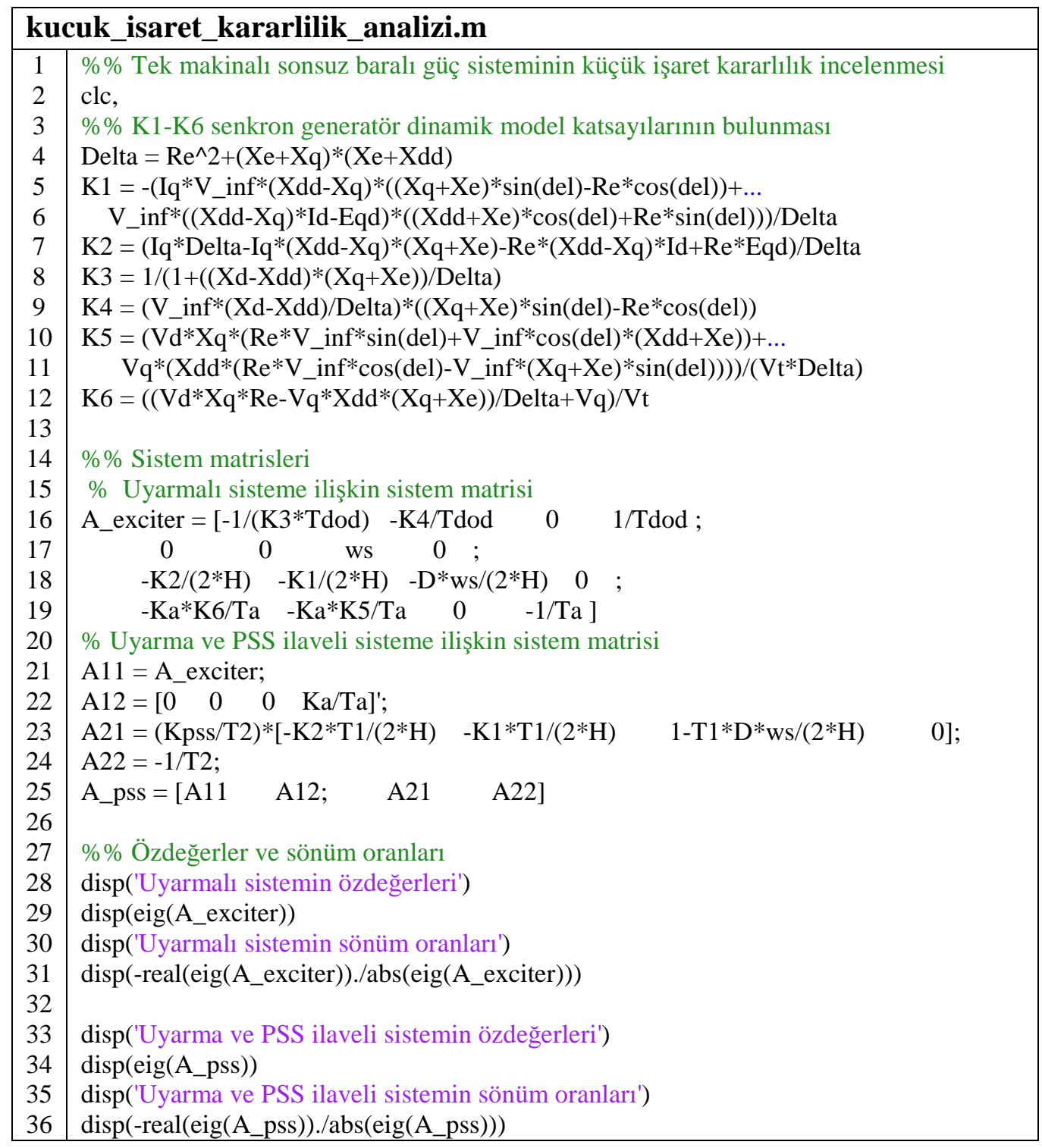

Bu iki sistemin özdeğerleri $\left(\lambda_{i}=\sigma_{i} \pm j \omega_{i}\right)$ ve sönüm oranları $\left(\zeta_{i}=-\sigma_{i} / \sqrt{\sigma_{i}^{2}+\omega_{i}^{2}}\right)$ Tablo 7'de verilmiştir. 
Tablo 7. Sistem özdeğerleri ve sönüm oranları.

\begin{tabular}{|l|l|l|}
\hline Sistem Türü & Özdeğerler & Sönüm Oranlar1 \\
\hline \multirow{3}{*}{ PSS' siz sistem } & $\lambda_{1,2}=-0.0871 \pm j 7.1139$ & 0.0122 \\
\cline { 2 - 3 } & $\lambda_{3,4}=-2.5885 \pm j 8.502$ & 0.2913 \\
\hline \multirow{4}{*}{ PSS'li sistem } & $\lambda_{1,2}=-0.86026 \pm j 7.0766$ & 0.1207 \\
\cline { 2 - 3 } & $\lambda_{3,4}=-1.6327 \pm j 8.5575$ & 0.1874 \\
\cline { 2 - 3 } & $\lambda_{5}=-10.365$ & 1 \\
\hline
\end{tabular}

Tablo 7'den açıkça anlaşılacağı üzere, sistemin PSS'siz çalışması durumunda $\lambda_{1,2}$ elektromekanik modu kötü sönümlüdür çünkü özdeğerlerin negatif gerçek kısmı küçüktür ve sönüm oranları da \%1.22'dir. Bununla beraber sistemin PSS ilave edilerek çalışması durumunda $\lambda_{1,2}$ özdeğerlerinin negatif gerçek kısmı daha solda yer alır ve sönüm oranları da \%12.07 değeri alarak sistemin salınımlarını önemli ölçüde iyileştirir. Özdeğer analizi sonuçları, PSS cihazının eklenmesinin elektromekanik mod sönümünü iyileştirdiğini göstermektedir. Tüm bu sonuçlar elde edilirken paket programdaki kucuk_isaret_kararlilik_analizi.m dosyasından yararlanılmıştır.

\subsection{Geçici hal kararlılık çalışmaları için Simulink tabanlı modelin oluşturulması}

Bu bölüm çalışmanın en önemli eğitici tarafını oluşturan doğrusal olmayan TMSB güç sisteminin Simulink yardımıyla nasıl modelleneceğini detaylı ve anlaşılır bir biçimde göstermektedir. Genel olarak uyarma ve PSS ilaveli TMSB sistemin Simulink tabanlı model yapısı inşa edilirken kullanılacak diferansiyel ve cebirsel denklemleri toplu şekilde yeniden yazılırsa;

$\dot{\delta}=\omega-\omega_{s}=\omega_{s} \Delta \omega$

$\dot{\omega}=\frac{\omega_{s}}{2 H}\left[T_{m}-T_{e}-D\left(\omega-\omega_{s}\right)\right]$

$\dot{E}_{q}^{\prime}=-\frac{1}{T_{d o}^{\prime}}\left(E_{q}^{\prime}+\left(X_{d}-X_{d}^{\prime}\right) I_{d}-E_{f d}\right)$

$\dot{E}_{f d}=\frac{1}{T_{a}}\left(-E_{f d}+K_{a}\left(V_{r e f}-V_{t}+V_{S}\right)\right)$

$X_{q} I_{q}-V_{d}=0$

$E_{q}^{\prime}-V_{q}-X_{d}^{\prime} I_{d}=0$

$R_{e} I_{d}-X_{e} I_{q}=V_{d}-V_{\infty} \sin \delta$

$X_{e} I_{d}+R_{e} I_{q}=V_{q}-V_{\infty} \cos \delta$ 
$V_{t}=\sqrt{V_{d}^{2}+V_{q}^{2}}$

Şekil 5 ve 6 sirasiyla, (42)-(43) ile (44)-(45) diferansiyel denklemlerin Simulink ortamında modellenmesini göstermektedir. (42) denklemindeki $\omega_{s}=2 \pi f$ ve (43) denklemindeki elektriksel güç $T_{e}=E_{q}^{\prime} I_{q}+\left(X_{q}-X_{d}^{\prime}\right) I_{d} I_{q}$ 'dir. Şekil 5 ve 6'da toplam dört adet $1 / s$ bloku mevcuttur ve içlerine başlangıç koşulları eklenmiştir.

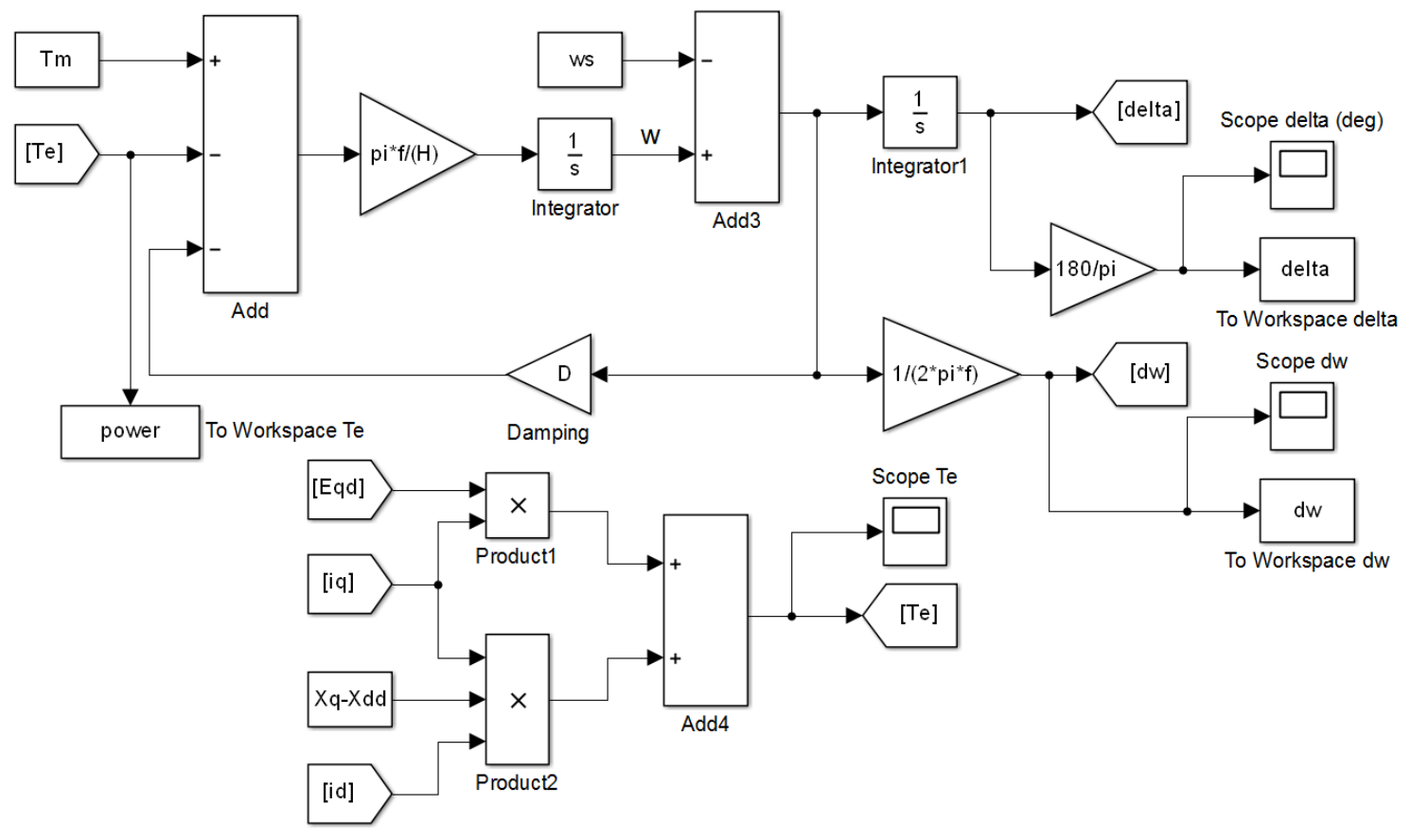

Şekil 5. Simulink bloklarla (42) ve (43) diferansiyel denklemlerinin modellenmesi.

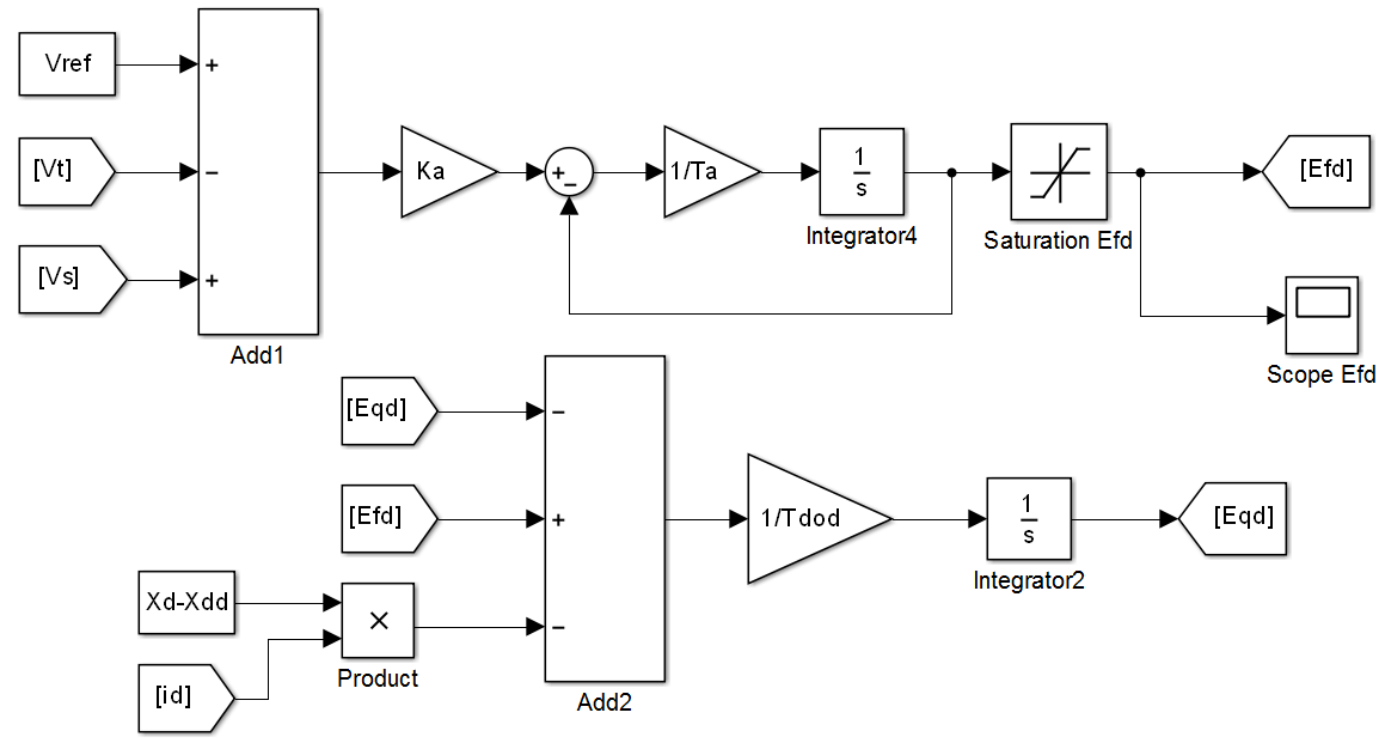

Şekil 6. Simulink bloklarla (44) ve (45) diferansiyel denklemlerinin modellenmesi.

(46) ile (47) denklemleri stator cebirsel denklemlerini; (48) ile (49) denklemleri şebeke denklemlerini ve (50) denklemi ise generatör uç gerilim büyüklüğü denklemini 
göstermekte olup, bu beş denkleme ilişkin Simulink tabanlı model Şekil 7'de gösterilmiştir. Şebeke denklemlerindeki $R_{e}$ direnci ihmal edilmiştir.

Tek makinalı güç sistemlerinin kararlılık analizleri için tasarlanan programın genişletilebilme özelliğini kullanarak sisteme PSS eklentisi yapılabilir. Blok diyagramı Şekil 4'te verilen PSS'nin Simulink modeli Şekil 8'de verilmiştir. PSS'nin temizleme bloku ihmal edilmiştir.

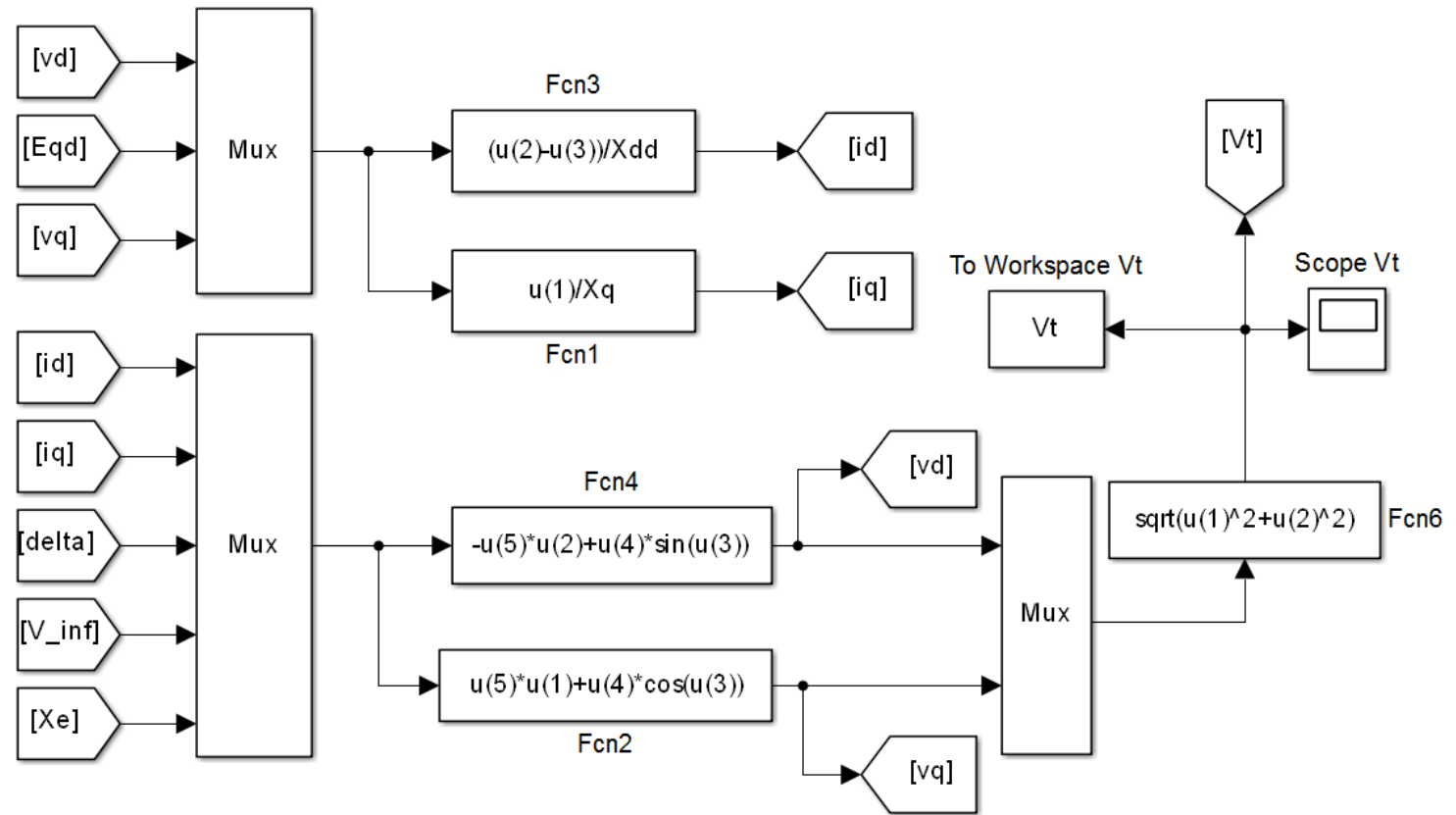

Şekil 7. Simulink bloklarla (46)-(50) cebirsel denklemlerinin modellenmesi.

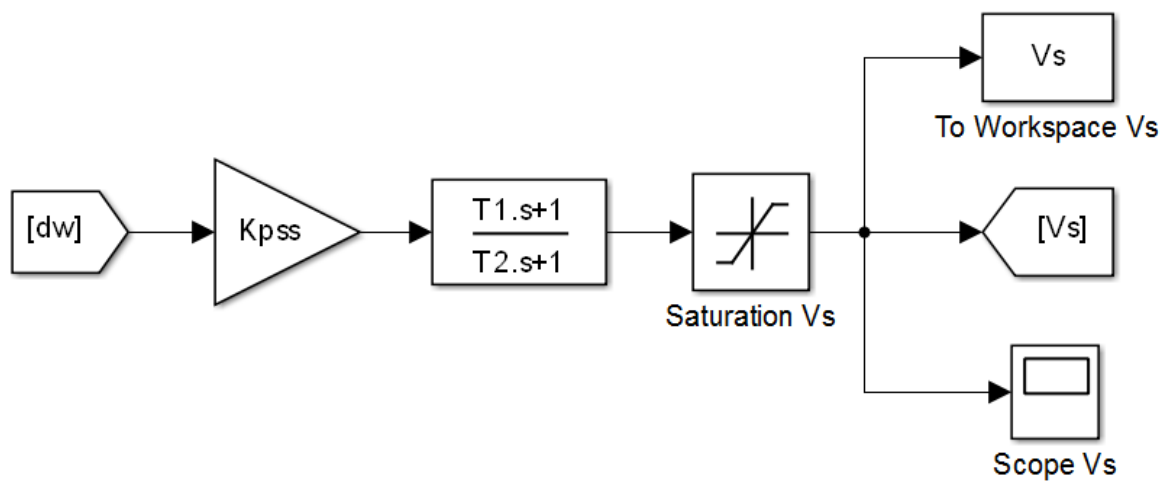

Şekil 8. Hız sapması girişli PSS’nin Simulink modeli.

TMSB sisteme bir arıza uygulanırsa, sistemde arıza öncesi, esnası ve sonrası olmak üzere üç farklı çalışma durumu oluşur. Arıza durumlarına göre $V_{\infty}$ sonsuz bara gerilimi ve $X_{e}$ reaktansının Simulink modeli Şekil 9'da verilmiştir.

Zaman bölgesi simülasyonunda kullanılan konfigürasyon parametreleri Şekil 10'da gösterilmiştir. Gerekmesi durumunda bu parametrelerde dilenen değişiklikler basitçe yapılabilir. Ayrıca, geçici hal kararlılık için geliştirilen Simulink tabanlı modeller 
yardımıyla PSS eklenmiş sistem ile kontrolsüz sistemin zaman cevapları karşılaştırılabilir ve PSS cihazının sistem üzerindeki pozitif etkileri de görülebilir.

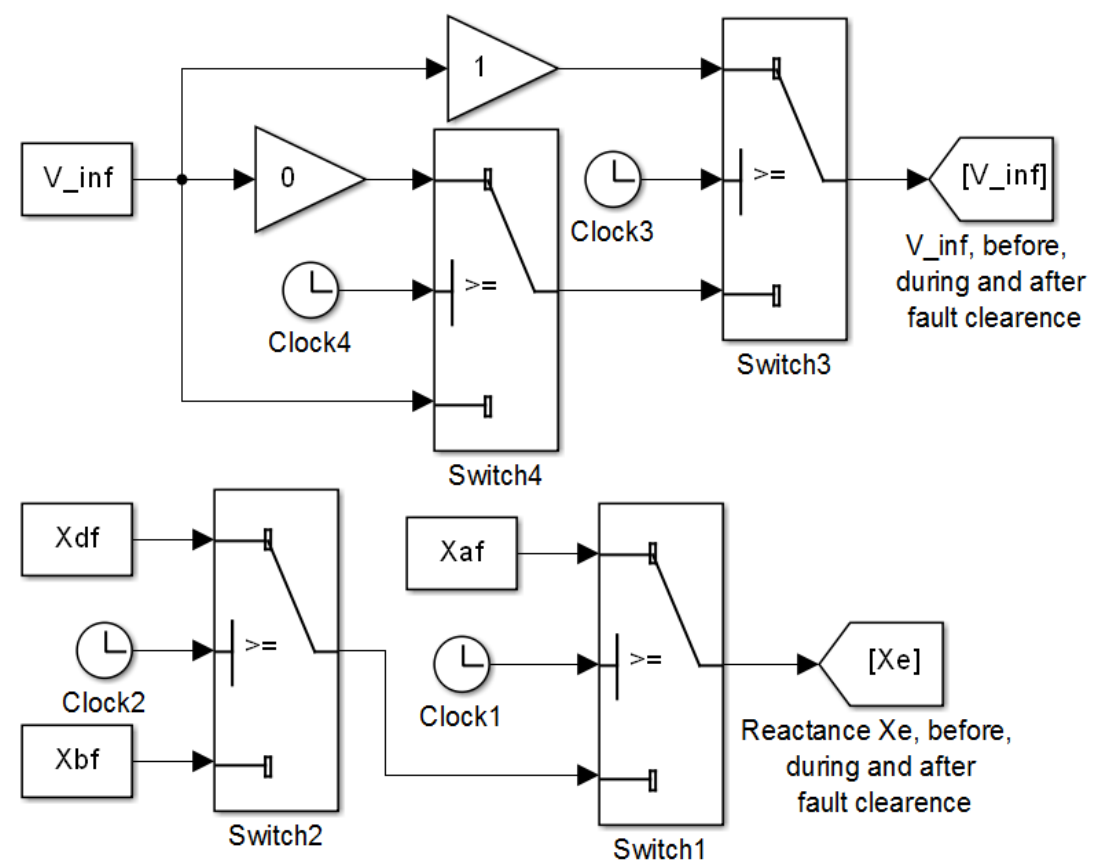

Şekil 9. Üç farklı arıza durumu için $\mathrm{V}_{\infty}$ sonsuz bara gerilimi ve $\mathrm{X}_{\mathrm{e}}$ reaktansının Simulink modeli.

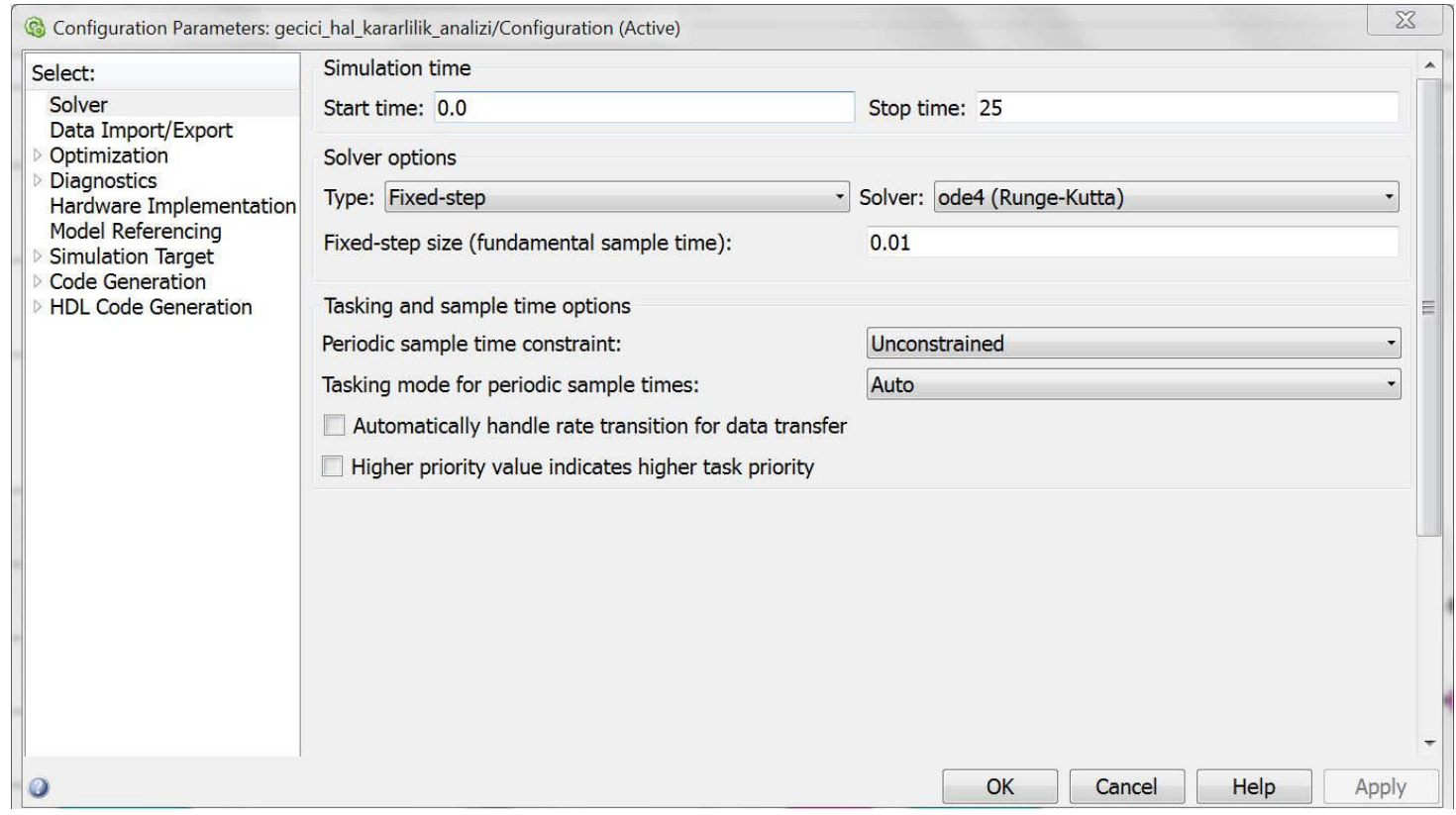

Şekil 10. Seçilen konfigürasyon parametreleri.

TMSB güç sisteminin geçici hal kararlılık çalışması için tasarlanan ve Şekil 5-9'daki Simulink modellerini tamamiyla içeren paket programdaki gecici_hal_kararlilik_analizi.mdl adlı Simulink dosyasının modelleme avantajını, geçerliliğini ve etkinliği ispatlamak amacıyla $t=5$ s'de generatör uçlarına üç-fazlı bir arıza uygulandı. Arıza $100 \mathrm{~ms}$ (6 devir) devam ettikten sonra ilgili arıza kaldırılmak 
suretiyle sistem önceki haline getirildi. Bu durum için Tablo 3'teki $t \_p r e$ ve $t$ fault değerleri sırasıyla 5 ve 0.1 olarak girilir. Bu büyük arızaya maruz kalan güç sisteminin sistem cevapları Şekil 11-13'te verilmiştir. Her bir şekil iki simülasyon sonuçlarını içerir: Uyarmalı sistem (PSS' siz sistem) ile uyarma ve PSS ilaveli sistem. Şekil 11-13 sırasıyla $\delta$ güç açısı, $\Delta \omega$ hız sapması ve $T_{e}$ elektriksel güç çıkışı cevaplarını göstermektedir. Sistem cevapları çiziminde, geliştirilen programda mevcut olan rotor_acisi_cizimi.m, hiz_sapmasi_cizimi.m ve elektriksel_guc_cizimi.m dosyalarından yararlanılmıştır.

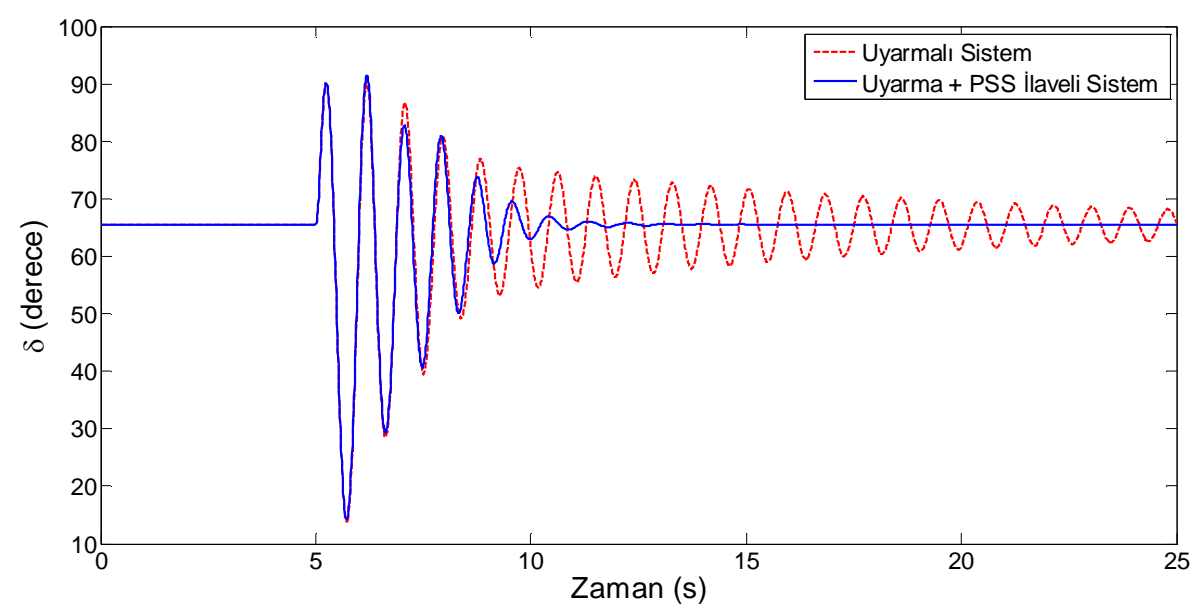

Şekil 11. $\delta$ güç açısının grafiğgi.

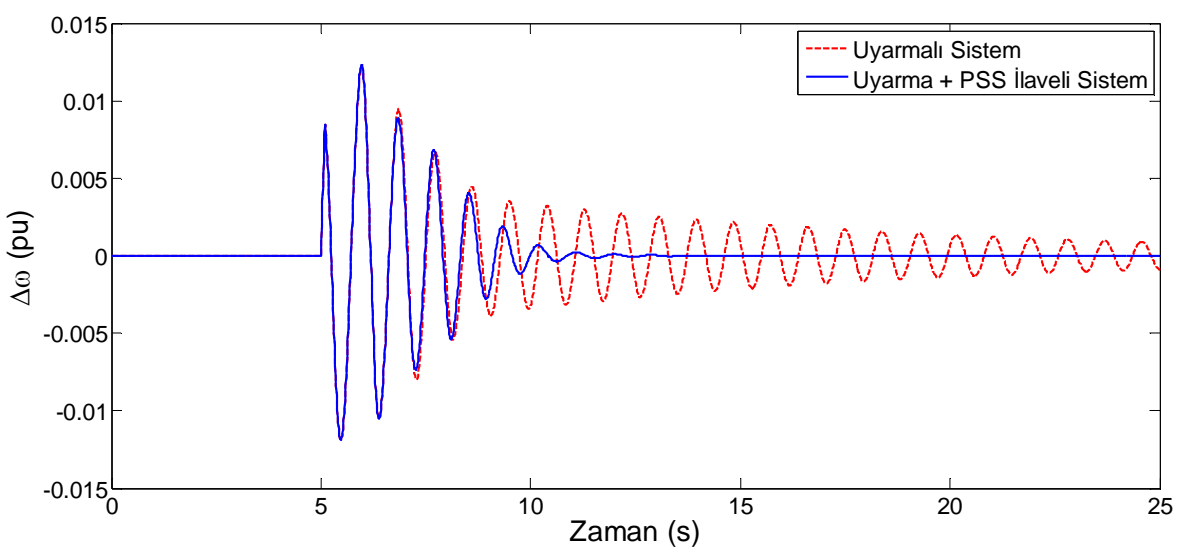

Şekil 12. $\Delta \omega$ rotor hız sapmasının grafiği. 


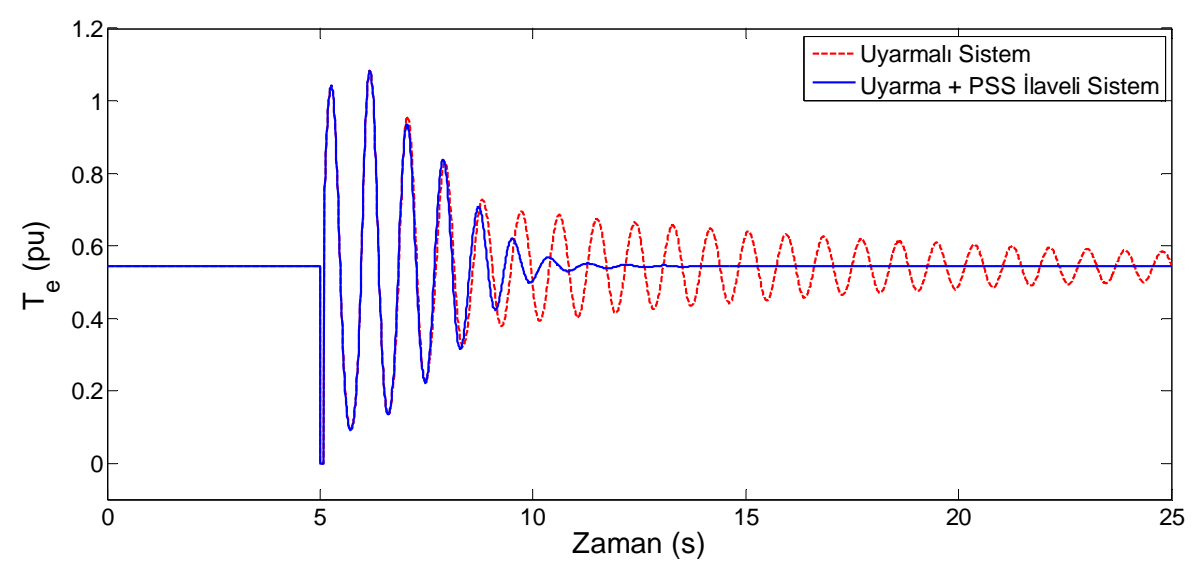

Şekil 13. $\mathrm{T}_{\mathrm{e}}$ elektriksel güç çıkışının grafiği.

Simülasyon şekillerden açıkça görüleceği gibi, yalnızca uyarma içeren sistem kararlıdır ancak salınımlar çok geç sönmektedir. Bununla birlikte sisteme PSS ilavesi yapılması durumunda, sistemin geçici hal kararlılık performansı iyileşmekte ve güç sistem salınımları daha hızlı sönümlenmektedir.

\subsection{Geliştirilen MATLAB/Simulink tabanlı programın ĕgitim alanında kullanımı}

Programdaki kod ve modellerin esnek, basit ve açık yapılı olmalarından dolayı kodlar ve Simulink modelleri üzerinde değişikler kolaylıkla yapılabilir. Esnek alternatif akım iletim sistemleri (Flexible AC Transmission System, FACTS), türbinler ve hiz regülatörü gibi diğer yapılar programa entegre edilerek genişletilebilir. Ayrıca paket program kullanılarak geleneksel ve sezgisel optimizasyon teknikleri ile kontrolör parametre optimizasyonu işlemi de kolaylıkla yapılabilir. Yazarlar olarak, bu çalışmanın sonuçları ve paket programın üniversitelerin Elektrik Mühendisliği yüksek lisans bölümlerinde verilen Enerji Sistemlerinin Kararlılığı (Power Systems Stability) dersinin daha verimli ve anlaşılır olmasına katkı sağlayacağına inanıyoruz.

Ayrıca, bu çalışmada TMSB güç sisteminin küçük işaret kararlılık ve geçici hal kararlılık analizleri için geliştirilen MATLAB/Simulink tabanlı program eksiksiz olarak bu konularda araştırma ve proje yapan öğrenci ve akademisyenlere açıktır ve programa [14]'ten ulaşabilirler.

\section{Sonuç}

$\mathrm{Bu}$ çalışma TMSB güç sistemlerinin kararlılığının MATLAB/Simulink ortamında geliştirilen paket bir program aracılığıyla incelenmesini ele almaktadır. Tasarlanan ve özellikle eğitici yönü olan yeni program, sahip olduğu basit kodlarla yazılma, esneklik, genişletilme, kodlara ve modellere erişebilme özellikleri nedeniyle tek makinalı güç sistemlerinin küçük işaret kararlılık ve geçici hal kararlılık analizlerini çok etkin ve başarılı bir şekilde yapabilmektedir. MATLAB/Simulink tabanlı önerilen programın performansı ve geçerliliğini belirlemek amacıyla literatürde mevcut olan uyarma ve PSS eklentili örnek bir sistem ele alındı. Yapılan analizler ve simülasyon sonuçları neticesinde programın kararlılık çalışmaları üzerine öğretici ve güçlü bir araç olduğu kanısına varıldı. Ayrıca, program Elektrik Mühendisliğinde yüksek lisans düzeyindeki Enerji Sistemlerinin Kararlılığı dersinde destekleyici bir araç olarak kullanılabilir. 
Eğitim ve araştırma amaçları için geliştirilen açık kaynak kodlu yazılım ilgili web sayfasından erişilmektedir.

\section{Teşekkür}

Çalışmanın yönlendirilmesi ve sonuçlandırılmasında emeği geçen Sayın Yusuf Ali Ekinci'ye teşekkür ederiz.

\section{Kaynaklar}

[1] Ekinci, S., Zeynelgil, H.L., Demiroren, A., A didactic procedure for transient stability simulation of a multimachine power system utilizing SIMULINK, International Journal of Electrical Engineering Education, 53(1), 54-71, (2016).

[2] Kundur, P., Power System Stability and Control, McGraw-Hill, New York, (1994).

[3] Ekinci, S., Çok makinalı güç sisteminde açısal kararlılık analizi ve kontrolör parametre optimizasyonu, Doktora Tezi, İstanbul Teknik Üniversitesi, Fen Bilimleri Enstitüsü, İstanbul, (2015).

[4] Milano, F., An Open Source Power System Analysis Toolbox. IEEE Transactions on Power Systems, 20(3), 1199-1206, (2005).

[5] Chow, J.H. ve Cheung, K.W., A toolbox for power system dynamics and control engineering education and research. IEEE Transactions on Power Systems, 7(4), 1559-1564, (1992).

[6] Allen, E., White, N.L., Yoon, Y., Chapman, J., Ilic, M., Interactive objectoriented simulation of interconnected power systems using SIMULINK. IEEE Transactions on Education, 44(1), 87-94, (2001).

[7] Patel, R., Bhatti, T.S., Kothari, D.P., MATLAB/Simulink-based transient stability analysis of a multi-machine power system. International Journal of Electrical Engineering Education, 39(4), 320-336, (2002).

[8] Demiroren, A., Zeynelgil, H.L., Modelling and Simulation of synchronous machine transient analysis using SIMULINK. International Journal of Electrical Engineering Education, 39(4), 337-346, (2002).

[9] Cho, Y.S., Park, J., Jang, G., A novel tool for transient stability analysis of largescale power systems: Its application to the KEPCO system. Simulation Modelling Practice and Theory, 15(7), 786-800, (2007).

[10] Gelen, A., Yalcinoz, T., An educational software package for Thyristor Switched Reactive Power Compensators using Matlab/Simulink. Simulation Modelling Practice and Theory, 18(3), 366-377, (2010).

[11] Ekinci, S., Demiroren, A. ve Zeynelgil, H.L., PowSysGUI: A new educational software package for power system stability studies using MATLAB/Simulink. International Journal of Electrical Engineering Education, 54(4), 283-298, (2017).

[12] Sauer, P.W., Pai, M.A., ve Chow, J.H. Power System Dynamics and Stability: With Synchrophasor Measurement and Power System Toolbox, Hoboken, NJ, USA : IEEE Press, Wiley, (2017).

[13] Mondal, D., Chakrabarti, A. ve Sengupta, A., Power System Small Signal Stability Analysis and Control, London, Academic Press, (2014).

[14] http://mmf.batman.edu.tr/Personel/SERDAR-EKINCI/438/847?o=1, (14.03.2018) 